\title{
Development and Validation of a LC-MS/MS Method to Determine Lansoprazole in Human Plasma
}

\author{
Ramanlal N. Kachave, ${ }^{*}$, Mayura Kale ${ }^{2}$ and Rajendra D. Wagh ${ }^{3}$ \\ ${ }^{l}$ Jawaharlal Nehru Technological University Kakinada - Andhra Pradesh 500 003, India; Amrutvahini College of \\ Pharmacy, Amrutnagar, P.O. Sangamner (S.K.), 422608, India \\ ${ }^{2}$ Government College of Pharmacy Aurangabad , Maharashtra , 431005, India \\ ${ }^{3}$ ARA College of Pharmacy, Nagaon, Dhule, 424 005, India
}

\begin{abstract}
A rapid and sensitive liquid chromatography-tandem mass spectrometric (LC-MS/MS) assay method has been developed and fully validated for the determination of lansoprazole (LNZ) in human plasma. Pantaprazole was used as an internal standard (IS). Analytes and the internal standard were extracted from human plasma by solid-phase extraction technique using Oasis HLB, Oasis Max, Varian Bond Elute Plexa, Orochem cartridges. The reconstituted samples were chromatographed on a thermo hypurity Advance, $50 \mathrm{X} 4.6 \mathrm{~mm}, 5 \mu$ by using acetonitrile and $2 \mathrm{mM}$ ammonium acetate solution $(80: 20 \mathrm{v} / \mathrm{v})$ as the mobile phase at a flow rate of $1.0 \mathrm{~mL} / \mathrm{min}$. Detection was carried out LC-MS/MS (API 3000) in negative ion mode. The calibration curves obtained were linear $\left(\mathrm{R}^{2}-0.999\right)$ over the concentration range of $4.50-2800.00$ $\mathrm{ng} / \mathrm{ml}$ for lansaprazole. The results of the intra- and inter-day precision studies were well within the acceptable limits. The overall average recoveries of analyte and IS were found to be $92.10-99.11 \%$. The analyte were found to be stable of stability study. Developed and validated analytical method was found to be simple, rapid, specific, sensitive, precise and cost effective than reported methods. The method has been successfully applied to the investigation of a preclinical pharmacokinetic study with desired precision and accuracy along with high throughput.
\end{abstract}

Keywords: Lansoprazole, liquid chromatography, MS/MS, pantaprazole.

\section{INTRODUCTION}

Lansoprazol (Fig. 1A) and Pantaprazole (Fig. 1B) belongs to a class of anti-secretory compounds, the substituted benzimidazoles, that do not exhibit anticholinergic or histamine $\mathrm{H}_{2}$-receptor antagonist properties, but rather suppress gastric acid secretion by specific inhibition of the $\left(\mathrm{H}^{+}, \mathrm{K}^{+}\right)$-ATPase enzyme system at the secretory surface of the gastric parietal cell. This enzyme system is regarded as the acid (proton) pump within the parietal cell, lansoprazole has been characterized as a gastric acid-pump inhibitor, in that it blocks the final step of acid production. This effect is dose-related and leads to inhibition of both basal and stimulated gastric acid secretion irrespective of the stimulus. Lansoprazol does not exhibit anticholinergic or histamine type-2 antagonist activity [3-9].

As per the literature, several LC-MS/MS methods have been reported for the determination of Lansoprazole individually or with other drugs in biological samples. In many studies, LNZ was used as the main analyte or as internal standard (IS), in that HPLC [1,2] by UV detection and UV spectroscopic methods were used, which were not suitable for clinical trials because of their low sensitivity [14-26]. Thus, the objective of the project was to develop and validate suitable method for estimation of unknown concentration of drug in plasma. A highly accurate,

*Address correspondence to this author at the Jawaharlal Nehru Technological University Kakinada, Andhra Pradesh, 500 003, India;

Tel: +91-9921871439; E-mail: raman_pharma@yahoo.co.in
(A)<smiles>Cc1c(OCC(F)(F)F)ccnc1CS(=O)c1nc2ccccc2[nH]1</smiles>

(B)<smiles>COc1ccnc(CS(=O)c2nc3cc(OC(F)(F)F)ccc3[nH]2)c1OC</smiles>

Fig. (1). Chemical structures of (A) Lansoprazole (B) Pantaprazole. sensitive, specific and reproducible LC-MS/MS method for the quantification of Lansoprazole using commercially available IS from small volumes of human plasma with a simple Solid Phase Extraction process was developed and validated [10-13]. Developed and validated analytical method was found to be simple, rapid, specific, sensitive, precise and cost effective than the reported methods. The method has been successfully applied to the investigation of a preclinical pharmacokinetic study with desired precision and accuracy along with high throughput [27-29]. 


\section{EXPERIMENTAL}

\subsection{Chemicals and Reagents}

Acetonitrile (HPLC grade, Merck), Ammonium acetate (HPLC grade, Merck), Human plasma, Milli-Q/HPLC water (In House), Methanol (HPLC grade, Merck), pantaprazole working standard (IS), Lansoprazole reference standard were provided by Wockhardt Research Centre, Aurangabad.

\subsection{Instrumentation and Chromatographic Conditions}

An HPLC system (Shimadzu, Kyoto, Japan)consisting of a Thermo Hypurity Advance, 50 X $4.6 \mathrm{~mm}, 5 \mu$, binary LC20AD prominence pump, an auto sampler (SIL-HTc) and a solvent degasser (DGU-20A3) was used for the study. Aliquots of the processed samples $(10 \mu \mathrm{L})$ were injected into the column, which was kept at $40 \pm 1^{0} \mathrm{C}$. The isocratic mobile phase, a mixture of Acetonitrile: $2 \mathrm{mM}$ Ammonium Acetate $(80: 20 \% \mathrm{v} / \mathrm{v})$ was delivered at $1.0 \mathrm{~mL} / \mathrm{min} \mathrm{LC}$ MS/MS (API 3000) in negative ion mode. Lansoprazole $\mathrm{m} / \mathrm{z}$ 370.20/252.10 Pantaprazole (IS) m/z 384.20/200.00 in Table 2. The parameters set were curtain gas, gas 1 , and gas 2 (nitrogen) as 40, 40, and 60 units, respectively, while Dwell time was $300 \mathrm{~s}$ and source temperature was $500{ }^{0} \mathrm{C}$. Ion spray voltage $4500 \mathrm{~V}$ unit mass resolution was set in an Q1 and Q3 analyzer and the main working parameters are summarized in Table 1. The developed and optimized analytical method has been validated for quality control samples. The linearity range was found to be $4.50 \mathrm{ng} / \mathrm{ml}$ $2800.00 \mathrm{ng} / \mathrm{ml}$ with regression value $\left(\mathrm{r}^{2}\right) 0.999$.

\subsection{Preparation of Standard Solutions}

Lansoprazole stock solution: Approximately $25 \mathrm{mg}$ of LNZ was weighed and transferred to $50 \mathrm{~mL}$ volumetric flask containing $10 \mu 1$ Liquor ammonia $(25 \%)$. Then Methanol was dissolved so that the volume reaches the mark to make approximately $500000.00 \mathrm{ng} / \mathrm{ml}$ stock solution. This stock solution was transferred in a reagent bottle with appropriate label and stored at $2-8{ }^{\circ} \mathrm{C}$. Further dilutions of LNZ were prepared in dilution solution for spiking in plasma. The stock solution must be used within 28 days from the date of preparation. However if stock solution stability generated later with maximum generated stability period.

Pantaprazole (Internal standard) stock solution: Approximately $25 \mathrm{mg}$ of PNZ was weighed and transferred to $25 \mathrm{~mL}$ volumetric containing $10 \mu \mathrm{l}$ of Liquor Ammonia to get 1000000 $\mathrm{ng} / \mathrm{mL}$ stocks with methanol. Stock solution was transferred in a reagent bottle with appropriate label and stored at $2-8{ }^{\circ} \mathrm{C}$

Table 1. Tandem mass working parameters.

\begin{tabular}{|c|c|}
\hline Parameter & Value \\
\hline \hline CAD gas & 2 \\
\hline Nebulizer Gas & 14 \\
\hline Curtain gas & 12 \\
\hline Ion Spray Voltage & 4500 volts \\
\hline Temperature & $500^{\circ} \mathrm{C}$ \\
\hline
\end{tabular}

\subsection{Preparation of Standard Solutions for $\mathrm{CC}$ and QC of Drug LNZ}

The selected range for validation was from $4.5 \mathrm{ng} / \mathrm{mL}$ to $2800.00 \mathrm{ng} / \mathrm{mL}$ concentrations for LNZ. The quality control samples for LNZ were prepared at concentrations of $4.61 \mathrm{ng} / \mathrm{ml}$ (LLOQ), $11.54 \mathrm{ng} / \mathrm{mL}$ (LQC), $1153.49 \mathrm{ng} / \mathrm{mL}$ (MQC) and 2306.98ng/mL (HQC).

Table 2. Chromatographic conditions.

\begin{tabular}{|l|l|}
\hline Column & Thermo Hypurity Advance, 50 X $4.6 \mathrm{~mm}, 5 \mu$ \\
\hline Mobile phase & Acetonitrile and $2 \mathrm{mM}$ Ammonium Acetate solution(80:20 v/v) \\
\hline Rinsing solution & Acetonitrile: Milli Q Water $(80: 20 \mathrm{v} / \mathrm{v})$ \\
\hline Flow rate & $1.000 \mathrm{~mL} / \mathrm{minute}$ with splitter $(70 \%$ to Waste) \\
\hline Column oven temperature & $40 \pm 1^{\circ} \mathrm{C}$ \\
\hline Detection & $\begin{array}{l}\text { LC-MS/MS (API } 3000) \text { in negative ion mode. } \\
\text { Lansoprazole } \mathrm{m} / \mathrm{z} 370.20 / 252.10 \\
\text { Pantaprazole }(\mathrm{IS}) \mathrm{m} / \mathrm{z} 384.20 / 200.00\end{array}$ \\
\hline Sample Cooler Temperature & $5^{\circ} \mathrm{C} \pm 1{ }^{\circ} \mathrm{C}$ \\
\hline Injection volume & $\mu \mathrm{L}$ \\
\hline
\end{tabular}

Table 3. Precision and accuracy of the method for determining LNZ in plasma samples.

\begin{tabular}{|c|c|c|c|c|c|c|c|c|}
\hline \multirow{2}{*}{\multicolumn{2}{|c|}{ Analyte }} & \multirow{2}{*}{ Conc. Added (ng/mL) } & \multicolumn{3}{|c|}{ Intra-day Precision and Accuracy } & \multicolumn{3}{|c|}{ Inter-Day Precision and Accuracy } \\
\hline & & & Mean Found ng/mL) & \pm S.D. & $\% \mathrm{CV}$ & Mean Found ng/mL) & \pm S.D. & $\% \mathrm{CV}$ \\
\hline \multirow{4}{*}{ LNZ } & LLOQ QC & 4.61 & 4.320 & 0.2069 & 4.79 & 4.246 & 0.3997 & 9.41 \\
\hline & LQC & 11.54 & 11.044 & 0.2848 & 2.58 & 11.166 & 0.6575 & 4.89 \\
\hline & MQC & 1153.49 & 1124.715 & 34.315 & 3.14 & 1143.251 & 53.0277 & 4.64 \\
\hline & HQC & 2306.98 & 2179.283 & 34.81 & 1.64 & 2190.382 & 47.823 & 2.18 \\
\hline
\end{tabular}


Table 4. Ruggedness of lansoprazole.

\begin{tabular}{|c|c|c|c|c|}
\hline \multirow{2}{*}{ Sr. No. } & LLOQ QC & LQC & MQC & HQC \\
\cline { 2 - 5 } & 4.61 & 11.54 & 1153.49 & 2306.98 \\
\hline 1 & 3.81 & 11.24 & 1104.70 & 2104.40 \\
\hline 2 & 4.28 & 10.30 & 1098.16 & 2218.24 \\
\hline 3 & 3.69 & 10.38 & 1121.38 & 2134.99 \\
\hline 4 & 4.43 & 11.28 & 1077.09 & 2117.92 \\
\hline 5 & 4.33 & 10.71 & 1094.76 & 2111.75 \\
\hline 6 & 4.20 & 10.42 & 1134.69 & 2077.85 \\
\hline Mean & 4.123 & 10.722 & 1104.463 & 2127.858 \\
\hline \pm S.D. & 0.3010 & 0.4396 & 20.2984 & 48.1631 \\
\hline \% CV & 7.30 & 4.10 & 1.84 & 2.26 \\
\hline$\%$ Nominal & 89.44 & 92.91 & 94.84 & 92.24 \\
\hline
\end{tabular}

\section{RESULT AND DISCUSSION}

\subsection{Method Development}

The goal of this work was to develop and validate a simple, rapid, selective, and sensitive assay method for the extraction and quantitation of LNZ. To achieve the goal during method development, different options were evaluated to optimize sample extraction, detection parameters, and chromatography. LNZ was extracted by Solid Phase extraction by using the Varian Bond Elute Plexa. It was found to be the most reproducible and gave less batch variation when compared with other organic solvents. It was found that the best signal was achieved with (API 3000) in negative ion mode the isocratic mobile phase, a mixture of Acetonitrile: $2 \mathrm{mM}$ Ammonium Acetate $(80: 20 \% \mathrm{v} / \mathrm{v})$ was delivered at $1.0 \mathrm{~mL} / \mathrm{min}$. With this optimized mobile phase, the $\mathrm{m} / \mathrm{z}$ value of the parent ions of Lansoprazole 370.20/252.10 Pantaprazole (IS) 384.20/200.00. The spiked plasma was retrieved from the deep freezer and thawed in a water bath at room temperature. The thawed samples were vortexed to ensure complete mixing of the contents. $50 \mu \mathrm{l}$ of internal standard $(10000.0 \mathrm{ng} / \mathrm{ml})$ was added in prelabelled RIA vials except in blank samples where $50 \mu 1$ of dilution solution was added. A $250 \mu \mathrm{l}$ of the sample was added to it and the RIA vials. $500 \mu 10 \mathrm{Mm}$ Sodium Dihydrogen Orthophosphate was added and vortex again. The samples was extracted using SPE technique. Varian Bond Elute Plexa $30 \mathrm{mg} / \mathrm{cc}$ was conditioned on a Speed-disk pressure processor using $1 \mathrm{ml}$ Methanol followed by $1 \mathrm{ml}$ milli-Q water/HPLC grade water at a constant positive pressure. Prepared plasma samples were loaded and then washed with $1 \mathrm{ml}$ of Milli-Q water/ HPLC grade water then again washed with $1 \mathrm{ml}$ of $5 \%(\mathrm{v} / \mathrm{v})$ Methanol in water. The cartridges were dried under positive pressure and eluted with $2 \mathrm{ml}(1$ $\mathrm{ml} \times 2$ ) of Methanol. The elute was dried at $50^{\circ} \mathrm{C}$ under stream of nitrogen and reconstituted with $500 \mu$ l of reconstitution solution and filled into vials. The samples were analyzed on LC/MS/MS.

\subsection{Validation}

ICH guidelines and USFDA guidelines were followed for method validation [27-29] the method was validated for its selectivity, stability, linearity, accuracy, precision, and recovery.

\subsubsection{Selectivity}

The selectivity of the method was assessed by comparing chromatogram of blank plasma and spiked plasma. The retention times were $1.48 \mathrm{~min}$ for analyte and 1.47 for internal standard 1.47 represented in Figs. $(\mathbf{2}, \mathbf{3})$. There were no significant endogenous peaks. That could not interfere with retention time of Analyte and Internal standard. The results indicate that the method exhibited good selectivity.

$$
\begin{aligned}
& \% \text { Interferance } \\
& =\frac{\text { Area at RT of Analyte (or IS) in the blank matrix }}{\text { Mean of Area at RT of Analyte (or IS)in hte LLOQ }} \text { X100 }
\end{aligned}
$$

\subsubsection{Matrix Effect}

The ion suppression/enhancement in the signal were found \% CV 4.41 at low QC level and \%CV 2.48 at high QC level for analyte, indicating that the matrix effect of analyte is not obvious under these conditions.

$$
\begin{aligned}
& \text { Accuracy (\% Nominal) } \\
& =\frac{\text { Mean of Each QC concentration level }}{\text { Nominal Value }} \times 100 \\
& \text { Precision (\% CV) } \\
& =\frac{\text { S. D. at QC concentration level }}{\text { Mean of Each QC concentration Level }} \text { X100 }
\end{aligned}
$$

\subsubsection{Sensitivity}

The LLOQ signal-to-noise $(\mathrm{S} / \mathrm{N})$ values found for six injections of analyte at LLOQ concentration was 89.85 . The Limit of Detection (LOD) was $4.00 \mathrm{ng} / \mathrm{ml}$ and Limit of Quantitation (LOQ) was $4.60 \mathrm{ng} / \mathrm{ml}$. It can be concluded that the sensitivity is more for this method.

\subsubsection{Linearity}

Calibration curves were plotted as the peak area ratio versus analyte concentration. Calibration was found to be linear over the concentration range of $4.50 \mathrm{ng} / \mathrm{ml}$ to 2800.00 $\mathrm{ng} / \mathrm{ml}$. The linearity was represented by a linear regression equation as follows.

$\mathrm{Y}=269.8 \mathrm{x}+5.146\left(\mathrm{R}^{2}=0.999\right)$

\subsubsection{Precision and Accuracy}

The precision was less than $2.25 \%$ and the accuracy of the mean of measured concentrations ranged from 96.45 to $103.20 \%$. Precision and accuracy for this method were controlled by calculating the intra and inter-batch variations of QC samples in six replicates. The intra-batch precision and accuracy were between 1.64 to 4.79 and 93.71 to $97.59 \%$. Similarly, the inter-batch precision and accuracy were between 2.18 to 9.41 and 92.10 to $99.11 \%$ are 




Fig. (2). Blank + Internal slandered.

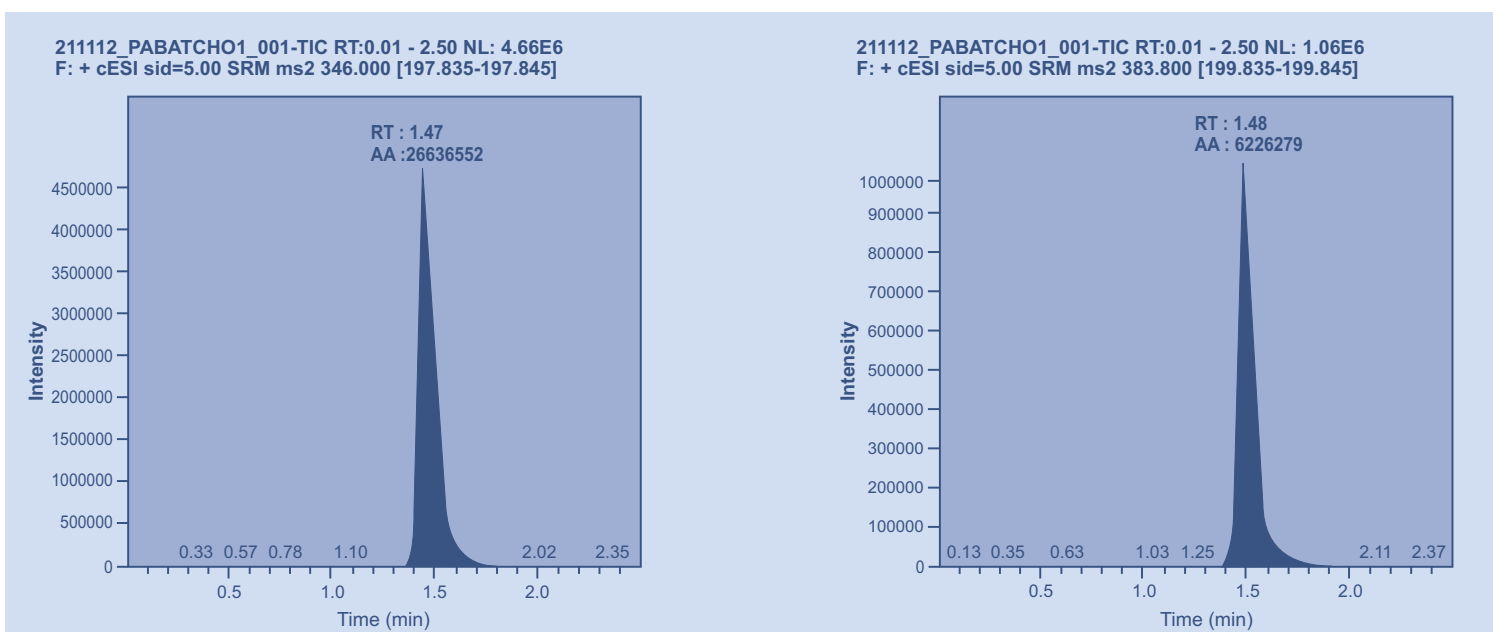

Fig. (3). Representative chromatograms for standard solution of LNZ and (IS) PNZ.

summarized in Table 3. These results indicate the adequate reliability and reproducibility of this method within the analytical range.

\subsubsection{Recovery}

The extraction recoveries was determined at three different concentrations, and were found to be $11.54 \mathrm{ng} / \mathrm{mL}, 1153.49 \mathrm{ng} / \mathrm{mL}$ and $2306.98 \mathrm{ng} / \mathrm{mL}$ respectively. The overall average recoveries of analyte and IS were found to be $92.10-99.11 \%$. Recoveries of the analyte and IS were high and consistent, precise and reproducible.

\subsubsection{Stability}

Analyte in plasma was subjected to three freeze/thaw cycles. The obtained accuracy was between $96.45 \%$ and $99.42 \%$ of the theoretical values. No significant degradation of the analyte was observed even after $48 \mathrm{~h}$ storage period in Autosampler tray and the final concentrations of analyte was found in between $96.42 \%$ and $92.08 \%$ of the theoretical values. In addition, the long-term stability of QC samples after 90 days of storage was at $-20^{\circ} \mathrm{c},-50^{\circ} \mathrm{c}$. The concentrations ranged from 92.24 to $95.13 \%$ for long term stability and room temperature stability for $48 \mathrm{~h}$ was also evaluated for Analyte and IS. The \% comparison response 101.81 to $99.64 \%$ for Room Temperature and Refrigeration stock solution stability studies. These results confirmed the stability of analyte human plasma for at least 90 Days at $20^{\circ} \mathrm{c},-50^{\circ} \mathrm{c}$.

\subsubsection{Reinjection Reproducibility}

Calibration was found to be linear over the concentration range of $4.50 \mathrm{ng} / \mathrm{ml}$ to $2800.00 \mathrm{ng} / \mathrm{ml}$. The precision was less than 3.09 to 2.62 and the accuracy of the mean of measured concentrations ranged from 98.24 to $99.94 \%$. This produced almost reproducible result.

\subsubsection{Dilution Integrity}

The dilution of samples should not affect the accuracy and precision (two times and four times as per dilution factor). Accuracy of 92.30 to $94.45 \%$ was observed.

\subsubsection{Ruggedness}

By method transfer, the Precision and Accuracy 1.84 to 7.30 and 89.44 to $92.08 \%$ was found showing reproducible results with Accuracy and Precision in Table 4.

\section{CONCLUSION}

Thus, the objective was to develop and validate suitable method for estimation of unknown concentration of drug in plasma. A highly accurate, sensitive, specific and reproducible LC-MS/MS method for the quantification of 
Lansoprazole using commercially available IS from small volumes of human plasma with a simple Solid Phase Extraction process was developed and validated. Developed and validated analytical method was found to be simple, rapid, specific, sensitive, precise and cost effective than the other reported methods. The method has been successfully applied to the investigation of a preclinical pharmacokinetic study with desired precision and accuracy along with high throughput.

\section{CONFLICT OF INTEREST}

The author confirms that this article content has no conflict of interest

\section{ACKNOWLEDGEMENTS}

The authors wish to thank Standard Lansoprazole and Pantaprazole reference standard was provided by Wockhardt Research Centre, Aurangabad. The authors extend thanks to the School of Pharmaceutical Sciences, JNTU-K, Kakinada and Management and Principal of Amrutvahini College of Pharmacy, Sangamner for their cooperation in the present research work.

\section{REFERENCES}

[1] Sethi, P.D. High Performance Liquid Chromatography; Quantitative Analysis of Pharmaceutical Formulations, $1^{\text {st }}$ ed.; CBS Publishers and Distributors Pvt. Ltd. : New Delhi, 2010, Vol. I, pp. 59-63.

[2] Sethi, P.D. High Performance Liquid Chromatography; Quantitative Analysis of Pharmaceutical Formulations, $1^{\text {st }}$ ed.; CBS Publishers and Distributors Pvt. Ltd. : New Delhi, 2010, Vol. I, pp. 11-14, 101-103.

[3] Brahmankar, M. Biopharmaceutics and Pharmacokinetics, $1^{\text {st }}$ ed.; Vallabh Prakashan: Delhi, 2005; pp. 282-283, 294.

[4] The Merck Index - An Encyclopaedia of Chemicals, Drugs, and Biological, $1^{\text {3th }}$ ed.; Merck Research Laboratories, Whitehouse Station. New Jersey, 2001.

[5] Joel, G. H.; Lee, E. L. The Pharmacological Basis of Therapeutics, $9^{\text {th }}$ ed.; Mc Graw Hill Publication: New York, 1996.

[6] Barar, F. S. K. Essentials of Pharmacotherapeutics, $4^{\text {th }}$ ed.; S. Chand \& Company Ltd. : New Delhi, 2000.

[7] Venkateshwarlu, V. Biopharmaceutics and Pharmacokinetics, $1^{\text {st }}$ ed.; Pharm Book Syndicate: Hyderabad, 2004, p. 331.

[8] Robert, E. N., Biopharmaceutics \& Clinical Pharmacokinetics, $4^{\text {th }}$ ed.; Marcel Dekker, New York, 2005, Vol. 3, p.352.

[9] Malcol, M., Thomas, N. Clinical Pharmacokinetics Concepts and Application, $3^{\text {rd }}$ ed.; Waverly Pvt Ltd.: New Delhi, 1996, p. 57.

[10] Willard. Instrumental Methods of Analysis, CBS Publishers: New Delhi, 1982, $6^{\text {th }}$ ed.; pp. 467-476.

[11] Guide to Solid Phase Extraction, Bulletin 910, Sigma-Aldrich Publications, 1998.

[12] Sharma, D.; Mittal, R.; Gupta, A.; Singh, K.; Nair A. Quantitative Bioanalysis by LC-MS/MS: A Review. J. Pharm. Biomed. Sci., 2010, 7(1), 1-9.

[13] Zwir-Ferenc, A.; Biziuk, M. Solid phase extraction technique trends, opportunities and application. Pol. J. Environ. Stud., 2006, 15(5), 677-690.
[14] Qi, S.; Weng, N. Analysis of Omeprazole and 5-OH Omeprazole in human plasma using hydrophilic interaction chromatography with tandem mass spectrometry Eliminating evaporation and reconstitution steps in 96-well liquid/liquid extraction. $J$. Chromatogr., 2006, 830(1), 135-142.

[15] Min, Song.; Xuan, Gao.; Taijun, Hang.; Aidong,Wen Simultaneous determination of Lansoprazole and its metabolites 5_hydroxy Lansoprazole and Lansoprazole sulphone in human plasma by LC-MS/MS: Application to a pharmacokinetic study in healthy volunteers. J. Pharm. Biomed. Anal., 2008, 48(4), 11811186.

[16] Basavaiah, K.; Ramakrishna, V.; Anil Kumar, U. R.; Udaya ,K. Spectrophotometric and high performance liquid-chromatographic determination of Lansoprazole in pharmaceuticals. Indian J. Chem. Technol., 2006, 13(6), 549-554.

[17] Naser, L. R.; Kevin, C. B.; Angela, D.M. A simple and sensitive Bioanalytical assay for simultaneous determination of Omeprazole and its three major metabolites in human blood plasma using RPHPLC after a simple liquid-liquid extraction procedure. $J$. Chromatogr., 2006, 848(2), 314-321.

[18] Muthu, K. S.; Selva, K. D.; Rajkumar, T.; Udhaya, K. E., Suba Geetha ,A.; Dinesh, D. Development and Validation of RP-HPLC method for the estimation of Lansoprazole in tablet dosage form. $J$. Chem. Pharm. Res., 2010, 5(2), 291-295.

[19] Balasekhara, R. C.; Sai, H.S.; Bahlul, Z. A.; Babu R. C.; Chandrasekhar, K. B.; Mukkanti, K.; Kanchanamala, K.; Rihana, P. S. Development and validation of a Sensitive Bioanalytical method for the quantitative estimation of Pantaprazole in human plasma samples by LC-MS/MS: Application to bioequivalence study. $J$. Chromatogr., 2010, 878(19), 1499-1505.

[20] Juliana, C. B.; Kenia, L.; Vanzolini, Q. B. C. Direct injection of native aqueous matrices by achiral-chiral chromatography ion trap mass spectrometry for simultaneous quantification of Pantoprazole and Lansoprazole enantiomers fractions. J. Chromatogr., 2011, 1218(20), 2865-2870.

[21] Parul, G.; Yazen, Al.; Gregory, A. R. Buspirone, Fexofenadine, and Omeprazole: Quantification of probe drugs and their metabolites in human plasma. J. Pharm. Biomed. Anal., 2011, 5(55), 1127-1135.

[22] Vaithiyanathan, S. J.; Rajappan, M.; Kannappan, V. Stabilityindicating HPLC method for the simultaneous determination of Pantoprazole, Rabeprazole, Lansoprazole and Domperidone from their combination dosage forms. Int. J. Drug Develop. Res., 2011 3(4), 32- 38 .

[23] Vijayaraghavan, R.; Jayababu, G.; Prasad, R.; Thirugnanam, P.E.; Gayathri ,S.; Sriraam, V.T. Bio-analytical method development and validation for Omeprazole using LC-MS/MS. Int. J. Pharm. Sci Res., 2011, 2(9), 2475-2481.

[24] Meixia, C.; Yu, Xia.; Zhiyu, Ma, Liang Li, Dafang H.; Xiaoyan, C. Validation of a chiral liquid chromatography-tandem mass spectrometry method for the determination of Pantaprazole in dog plasma. J. Chromatogr., 2012, (906), 85- 90.

[25] Shah, V. P.; Midha, K.K. Analytical methods validation bioavailability, bioequivalence and pharmacokinetic studies. Pharm. Res., 1992, 2(9), 588-592.

[26] Shah, V. P.; Midha, K. K.; Findlay, J. W. Bioanalytical method validation - a revisit with a decade of progress. Pharm. Res., 2000 , 17(2), 1551-1557.

[27] Code Q2A-Text on Validation of Analytical Procedure Step-3 Consensus Guideline, ICH Harmonised Tripartite Guideline, 1994.

[28] Code Q2B- Validation of Analytical Procedure Methodology Step4 Consensus Guideline, ICH Harmonised Tripartite Guideline, 1994

[29] ICH Harmonised- Tripartite Guideline; Validation of Analytica Procedures: Text and Methodology Q2 (R1); November, 2005. 